\title{
Initiated and received task interdependence and distributed team performance: the mediating roles of different forms of role clarity
}

\author{
Sut I Wong ${ }^{1}\left[\right.$ [ $\cdot$ Suzanne van Gils ${ }^{1}$ (i)
}

Received: 31 March 2021 / Accepted: 10 June 2021 / Published online: 25 June 2021

(c) The Author(s) 2021

\begin{abstract}
Distributed agile teams are increasingly employed in organizations, partly due to the increased focus on digital transformation. However, research findings about the performance of such teams appear to be inconsistent, calling for more research to investigate the conditions under which distributed agile teams may thrive. Given that task coordination is particularly challenging when team members are not co-located, the present study investigates the roles of the two types of task interdependence, i.e., initiated versus received task interdependence. Survey results from 191 participants working in distributed agile teams within three companies in Norway confirm our hypotheses. Specifically, we show that high initiated task interdependence is associated with higher role clarity of others, while received task interdependence is associated with higher role clarity of self, and that both subsequently result in higher team performance in distributed agile teams. Thus, we argue that each type of task interdependence contributes in a unique way to team performance in distributed agile teams.
\end{abstract}

Keywords Distributed agile teams $\cdot$ Received task interdependence $\cdot$ Initiated task interdependence $\cdot$ Role clarity of self . Role clarity of others $\cdot$ Team performance

\section{Introduction}

Rapid technological innovations, new forms of work arrangements, and organizational disruptions have prompted the need to re-examine underlying assumptions of job and team design that may no longer hold true (Langfred and Rockmann 2016; Oldham and Hackman 2010). It is increasingly common for organizations to organize in distributed agile teams, in which team members are geographically distributed and coordinate through computer-mediated communication tools to perform their work (Gilson, 2015). This allows individual team members to be flexible in solving their work tasks, yet at the same time, team members may be highly interdependent in coordinating and completing the team's focal goals (Hertel et al. 2005). For distributed teams to work in an agile manner, this often require high levels of collective self-managing behaviors, such as "managing their

Sut I Wong

sut.i.wong@bi.no

Suzanne van Gils

suzanne.v.gils@bi.no

1 BI Norwegian Business School, Nydalsveien 37, 0484 Oslo, Norway own workload, shifting work among themselves based on need and best of it, and participating in team decision making" (Highsmith 2004). In the current study, we investigate how different types of task interdependence in distributed teams affect their performance.

While being highly self-managing, distributed agile team members are also highly interdependent. They rely on each other being good at sharing materials, information, or expertise, to achieve the desired output or performance (Stray et al. 2018; Van der Vegt and Van de Vliert 2002). Task interdependence, which refers to the degree to which team members depend on one another to carry out work effectively (Rico et al. 2011), influences the team's coordination pattern (Orton and Weick 1990). Specifically, the more team members need each other's input to do their work, the more they would need to interact (Orton and Weick 1990). However, unlike co-located teams, the lack of opportunities for physical interaction challenges distributed teams' abilities to adjust and coordinate virtually (Hertel et al. 2005; Huang et al. 2010).

Despite the centrality of task interdependence for coordination in teams, we know little about how task interdependence may influence the way distributed agile team members associate themselves with their tasks and others in the teams 
virtually. Even for traditional co-located teams, the role of task interdependence in relation to team performance has been somewhat unclear or inconsistent (Bailey et al. 2010; D'Innocenzo, 2016). Nevertheless, some studies directly show that high task interdependence serves as a crucial factor for high-performing self-managing teams (Magpili and Pazos 2018). Studies that take a more fine-grained approach to investigate the relationship between task interdependence and team performance argue that some of the contradictory findings could be clarified by building on the distinction between initiated task interdependence- - the extent to which an individual team member has other team members who are dependent on their work to do their own, and received task interdependence-the extent to which an individual team member is affected by the workflow from other team members to complete their work (Kiggundu 1983; Morgeson and Humphrey 2006).

In the present study, we argue that the two types of task interdependence, initiated and received, relate differently to clarity employees have about the requirements for their own work (referred to as role clarity; Rizzo et al. 1970) as well as for the work of others in the team. We propose that while initiated task interdependence is likely to enhance the role clarity of others, received task interdependence is likely to stimulate the focus of one's own role clarity. Both processes enhance the performance in distributed agile teams simultaneously in unique ways, because as communication becomes less rich and less frequent due to the geographical dispersion, the need for role clarity of others and self is higher. By investigating the different effects of the two types of task interdependence relating to distributed team coordination, our intended contributions are twofold. First, we provide new insights into the different mechanisms of initiated and received task interdependence that influence performance in distributed agile teams (Magpili and Pazos 2018). Our findings aim to provide possible explanations for the inconsistent findings in the autonomy versus interdependence literature. Second, our research answers calls for more knowledge on how different work contexts, created by digital technologies, challenge current organizational theories and research (Colbert et al. 2016; Gilson et al. 2015).

\section{Theory and hypotheses}

\subsection{Distributed agile teams and team performance}

The term distributed teams refers to teams whose members use some form of digital communication technology as part of their work across locational, temporal, and relational boundaries to accomplish an interdependent task (Gilson et al. 2015). Distributed teams are argued to possess characteristics that distinguish them from traditional face-to-face teams (Martins et al. 2004). Traditional teams typically work physically close to each other, and the work of the team and its members is mostly coordinated face to face (Krumm et al. 2016). In contrast, distributed teams mostly coordinate and communicate their work by the use of technology and digital media, and at least one person in the team works from another location or time zone than the rest of the team members (Hertel et al. 2005). As distributed teams are enabled by computer-mediated communication tools, such as instant chat, video conferencing, online forums, etc., their team arrangements could make collaborating and knowledge sharing easier and less bureaucratic (Martins et al. 2004; Sarker et al. 2011). The use of distributed teams in organizations has grown substantially, and the use of distributed teams is anticipated to continue to grow in the future to increase organizational agility (Dulebohn and Hoch 2017). Although technologies are approached as a means to appropriate organizational strategies, the implementation of distributed teams can be challenging with undesired outcomes (Dutrénit 2004; Pasmore et al. 1982; Powell 1987).

While distributed team solutions are appreciated by some, others may find themselves less attached to the team or may find the work environment less social and more difficult to share knowledge (Cheshin et al. 2011; Hertel et al. 2005; Mesmer-Magnus et al. 2011). Thus, team members may see this digital communication technology enabled team setting as constraining rather than enabling. This is particularly so when they see technology as a structural property of organizations that reduces the flexibility with which they would go about their work (Orlikowski 1992), in our case, the ways in which team members may communicate among themselves. It is therefore not surprising that research findings on the effect of technology adoption on team performance (Orlikowski 2002; Ortiz de Guinea et al. 2012) have been inconsistent.

Indeed, research shows that although distributed teams can benefit from flexibility in terms of the time and location, distributed teams tend to perform less when compared to traditional teams (Gilson et al. 2015). This calls for more research on what can improve the effectiveness of distributed teams (Gilson et al. 2015). The current literature indicates that building trustworthy relationships among team members is an important strategy for developing distributed teams' effectiveness (Ford et al. 2017). Role clarity appears to play an important role, as it facilitates alignment of norms in the team and thereby improves satisfaction and performance (Henderson et al. 2016). Moreover, recent research has also indicated that the way in which distributed team members are interdependent on each other can influence the functioning of a distributed team (Wong and Berntzen 2019). 


\subsection{Types of task interdependence and role clarity}

A team member may both initiate and receive work within the same team. Although all team members share the same overall objectives (i.e., the team's focal goal), each individual may handle different portions of the task. As such, sometimes team members may perceive high levels of initiated task interdependence because they initiate the work of others, and at the same time, they depend on the completion of other team members' work, and perceive higher levels of received task interdependence. However, an asymmetric situation could also occur due to the changes in task demands in the teams and the various skills that the team members possess. For instance, a study by de Jong and Bal (2014) demonstrated that less-skilled workers are more dependent on more skilled workers of the team to do their jobs. Although the two types of task interdependence are related, they are conceptualized as unique task or job dimensions (Kiggundu 1983). However, there are currently only a few studies that have differentiated between the two forms of interdependence (e.g., Doerr et al. 2004; Morgeson and Humphrey 2006; Taggar and Haines 2006).

Doerr et al. (2004) clarified that initiated interdependence describes only half of a dyadic relationship and described that the two interdependencies can be related to different experiences. Specifically, a team member with high initiated task interdependence is likely to feel a great deal of responsibility for others' work in the team, as they are dependent on his/her inputs. On the other hand, team members with high received task interdependence may feel their job autonomy is reduced, as they cannot decide freely on how they may approach their work. However, the two task interdependencies should not been seen as black-and-white in terms of what type of task interdependence is good or bad, and instead should be perceived as different means to yield different ways of team functioning (Morgeson and Humphrey 2006).

\subsection{Role clarity of self and others}

Role clarity refers to the degree to which an individual has clarity of their behavioral requirements in their work situation (Rizzo et al. 1970). A role comprises a set of expectations about behavior of a certain position (Lapointe et al. 2014). Therefore, when role clarity is low, it implies that there is a lack of information available to the person about what is required for adequate performance of his/her role (Kahn et al. 1964; Henderson et al. 2016). Role clarity can be divided into perceived role clarity of the self and perceived role clarity of others. In a work setting, expectations about a worker's role are attributed to the worker by both the worker him/herself and by others who relate to the role in question (Rizzo et al. 1970). Therefore, in the current study, role clarity of self refers to the perception of having as much role relevant information regarding one's own role as the worker would like to have (Lyons 1971), while role clarity of others is concerned with the perception of having as much role relevant information as the worker would like to have regarding another's role.

For teams to perform their work well, it is important that each member of the team has a clear understanding of his/ her own role and how this role interacts with other team members' roles, as well as who is responsible for what task (Deeter-Schmelz 1997). A study by Henderson et al. (2016) reveals that each member of a distributed team simultaneously establishes role clarity for oneself and negotiates role clarity with others, which leads to higher team performance (Henderson et al. 2016). Indeed, individual perceived role clarity and role clarity of others are likely to be more important in a distributed team than traditional co-located team setting. Given that interpersonal relations between the focal person and the role senders are part of determining role expectations (Katz and Kahn 1966), due to the less social presence in communication in distributed teams (Sproull and Kiesler 1986), the forming of interpersonal relations, which is important in role sending, can be harder than in traditional co-located teams.

\subsection{Task interdependence, role clarity, and distributed agile team performance}

Cheng (1983) used a role-system perspective to explain that interdependence in organizations reflects a set of work roles, and when effective, each role carries certain information that complements other roles. In the present study, we argue that initiated versus received task interdependence are likely to be related to distributed agile team performance differentially through role clarity of self versus others, as shown in Fig. 1. In particular, we argue that high initiated task interdependence is likely to be associated with higher role clarity of others, while received task interdependence is likely to be associated with higher role clarity of self, and subsequently result in higher team performance in distributed agile teams.

Initiated task interdependence encompasses a responsibility that the initiating team member feels toward other team members relying on his or her work (Taggar and Haines 2006). Improvement in team performance corresponds to the extent to which initiated interdependence produces a sense of felt responsibility in a team member (Doerr et al. 2004). Being dependent upon can instill higher levels of self-efficacy (Taggar and Haines 2006), but also creates a need to meet expectations of team members that the person will facilitate the work of others (Doerr et al. 2004). If the level of initiated task interdependence within a team is high, it motivates the individual team member to tie team members more closely together (Burke et al. 2006). As such, the 
Fig. 1 The conceptual model
$\mathrm{H} 1$

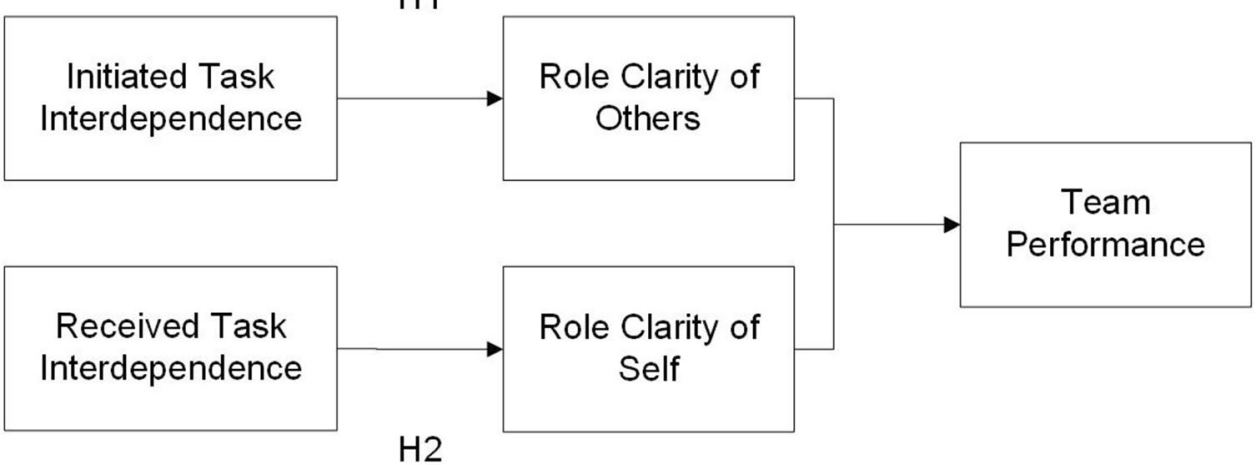

initiating task interdependence an individual team member experiences may serve as a motivation to facilitate other team members' work by engaging in more cooperative team behaviors. As a result of this cooperative team behavior, individuals will search and gain more insights into the roles of their team members. Research on cooperation and task interdependence shows that team members consider one another as more effective when they are high in initiated task interdependence (Taggar and Haines 2006), thus providing first evidence that the process described above may improve team performance.

The rationale about initiated task interdependence and role clarity of others highlights the need for team members to perform in accordance with their roles in their team to achieve coordination and subsequent success. We expect that when the level of initiated interdependence within the team is high, the individual team members are likely to facilitate each other's work by getting to know others' roles better and subsequently help the team to perform. Therefore, we hypothesize:

H1: Initiated task interdependence relates positively to role clarity of others, which in turn relates to distributed agile team performance.

There are other factors beyond motivation that contribute to success in distributed teams, thus it is perhaps too simple to view initiated task interdependence as helpful and received task interdependence as negligible. For example, Pearce and Gregersen (1991) found a positive relationship between received task interdependence and feelings of responsibility and job satisfaction. More specifically, in situations where a team member experiences received task interdependence, that is, perceives him or herself to be dependent on another team member to accomplish his or her own work, the motivation for coordination may be different from employees initiating interdependence (Doerr et al. 2004; Taggar and Haines 2006). For instance, Kiggundu (1983) did not find the same positive motivational impact for received interdependence in comparison to initiated interdependence in his seminal work. Instead, he found high levels of received interdependence to lead to less job involvement and to less engagement in overviewing the teams' strategies and behaviors thought to facilitate attainment of the common goal (Kiggundu 1983). In addition, initiated interdependence was found to positively relate to affective positive work and personal outcomes, while received interdependence did not relate to them (Kiggundu 1983). In other words, received task interdependence seems not to serve as a motivational factor to engage individual team members to pay attention to what is going on with other team members. Rather, received task interdependence causes the team member to focus more on him or herself.

This focus on the self allows for individual knowledge of what one should do to complete one's task (Lyons 1971). In the context of distributed agile teams, in which autonomous work is central, role clarity for the self can be essential for performing the task well. When workers perceive received task interdependence as high, they have much knowledge of who is involved in their work process and what they are personally responsible for (Pearce and Gregersen 1991), and as a result, self-role clarity is improved. Thus, while received role interdependence in itself may not promote team performance by directly improving cooperation among the team members, we suggest that it may positively influence selfrole clarity. Although received task interdependence may make individuals pay less attention to others, we expect, in contrast, that it would help the individual team members pay attention to what they need to fulfill their own roles. The more members of the distributed agile team are clear about their roles in the team, the better they will perform their part of the distributed task, thus enhancing team performance as a whole. Therefore, we posit that:

H2: Received task interdependence relates positively to role clarity of self, which in turn relates to distributed agile team performance.

Summarizing the above, we propose a model in which each type of task interdependence influences distributed 
team performance positively, albeit each based on its own distinct underlying process (see Fig. 1). While initiated task interdependence promotes performance through the cooperative mechanism of improved role clarity of others, received task interdependence promotes performance indirectly by fostering role clarity of self. To provide insight into this model, with employees working in different distributed teams, we opted for a quantitative approach and tested our model in a survey based field study with employees working in distributed teams, as described below.

\section{Methods}

\subsection{Sample}

We collected the data through an online survey distributed to individuals who were working in global distributed agile teams from three companies, including a global engineering company, a software development company, and a consultancy firm, all in Norway. These companies have been on the forefront of implementing digital solutions in the past years and have employed distributed teams in several functions as part of their global organizational strategies. The three participating companies also have offices in Europe and Asia. Among the three companies, we distributed our survey to 650 employees who worked in Norway and Asia. Most of the target participants were engineers. All of the participants were working in project-based distributed agile teams with various positions, including team lead, process engineers, quality control coordinators, specialists, senior structural and principal engineers, commercial managers, system responsible engineers, design control lead, software developers, etc. These teams were set up with a common goal of accomplishing the projects that they were assigned within the respective timelines. Due to this, they acted as a cross functional team and contributed to different aspects of the projects. A total of 191 completed responses were received between February and April in 2019, resulting in a $29.38 \%$ response rate.

Of the 191 respondents, $135(70.7 \%)$ were male and 54 (28.3\%) were female, with two (1.0\%) responses missing. Most of the respondents were between 35 and 45 years old (35.1\%), while the age group of 45-55 years old and the age group of over 55 both represented $23.0 \%$ each in our sample. Lastly, $16.2 \%$ of the respondents were between 25 and 35 years old and $2.6 \%$ were under 25 years old. Moreover, most of the respondents had obtained a master's degree (44.5\%), followed by those who had obtained a bachelor's degree (40.8\%), high school education (12.6\%), and a $\mathrm{PhD}$ degree (1.6\%). One respondent $(0.5 \%)$ did not report his/her educational attainment.

\subsection{Measures}

All the measures employed in this study were validated scales used in previous studies. Unless indicated otherwise below, answers were recorded on a 5-point Likert-scale ranging from $1=$ strongly disagree to $5=$ strongly agree . Respondents provided demographic information, including age, gender, education, the number of years worked in their current team, and the size of their team. As confirmed by the companies we collected the data from, the individuals in our sample were all working in global distributed teams and their working language was English. The questionnaire items were therefore in English to better suit their work nature.

\subsubsection{Initiated and received task interdependence}

The two types of task interdependence were measured using two scales from Morgeson and Humphrey (2006)'s Work Design Questionnaire. Each scale consisted of three items. Sample items are "Others depend directly on my job" (initiated) and "My job cannot be done unless others do their work" (received). In our sample, the values of Cronbach Alpha for initiated interdependence and received interdependence were 0.78 , and 0.73 , respectively, compared to 0.80 and 0.84 obtained by Morgeson and Humphrey (2006).

\subsubsection{Perceived role clarity of self and others}

Role clarity of self was measured using the four-item scale developed by Rizzo et al. (1970), and later modified by Boshoff and Allen (2000). A sample item is "I have clear, planned goals and objectives for my job". For role clarity of others, we adapted the role clarity of self scale and modified the respective items towards role clarity of other team members. A sample item is "I know the goals and objectives of other team members". The Cronbach alphas for role clarity of self and others were 0.84 and 0.90 , respectively.

\subsubsection{Team performance}

Team performance was measured by three items from the workgroup performance and efficiency scales developed by Jehn et al. (1999). Respondents were asked to evaluate their team performance in terms of efficiency, quality, and overall achievement, respectively, ranging from $1=$ very poor to $5=$ very good. A sample item is "How would you assess your team performance in terms of efficiency?" The value of Cronbach alpha was 0.83 .

\subsubsection{Control variables}

Control variables included were gender, age (i.e. under 25 , $25-35,35-45,45-55$, over 55), and level of education (i.e. 
Table 1 Means, standard deviations, Cronbach's alpha's and inter-correlations for the main composite variables

\begin{tabular}{|c|c|c|c|c|c|c|c|c|c|c|}
\hline & $M(\mathrm{SD})$ & 1 & 2 & 3 & 4 & 5 & 6 & 7 & 8 & 9 \\
\hline 1. Task interdependence initiated & $3.68(0.86)$ & $(0.78)$ & & & & & & & & \\
\hline 2. Task interdependence received & $4.18(0.74)$ & $0.39 * *$ & $(0.73)$ & & & & & & & \\
\hline 3. Role clarity self & $4.32(0.63)$ & 0.09 & $0.18 *$ & $(0.84)$ & & & & & & \\
\hline 4. Role clarity other & $3.90(0.79)$ & $0.23 * *$ & $0.15^{*}$ & $0.55^{* *}$ & $(0.90)$ & & & & & \\
\hline 5. Team performance & $4.10(0.53)$ & $0.18 *$ & -0.04 & $0.32 * *$ & $0.36^{* *}$ & $(0.83)$ & & & & \\
\hline 6. Age & Med 35-45 & -0.05 & 0.13 & 0.12 & -0.07 & -0.08 & & & & \\
\hline 7. Education & Med BSc & 0.05 & 0.05 & -0.12 & -0.12 & -0.06 & $-0.15^{*}$ & & & \\
\hline 8. Gender & $60 \%$ Male & -0.08 & -0.09 & 0.02 & 0.05 & 0.02 & -0.08 & 0.06 & & \\
\hline 9. Tenure with the team & $2.40(3.42)$ & 0.06 & 0.05 & 0.09 & 0.04 & 0.00 & $0.21 *$ & -0.07 & 0.08 & \\
\hline 10. Team size & $18.85(38.71)$ & -0.04 & 0.08 & 0.12 & $0.17 *$ & 0.02 & -0.07 & -0.07 & -0.09 & -0.05 \\
\hline
\end{tabular}

$N=191$

$* * p<0.01, * p<0.05$

high school diploma, bachelor's degree, masters' degree, and PhD). We included demographic variables, including age, gender, and education, as these could potentially account for variance in work-related assessments (Turban and Jones 1995). Furthermore, we measured team members' tenure with their teams measured in true numbers since individuals with longer tenure may have attained job-related knowledge about their teams ( $\mathrm{Ng}$ and Feldman 2010). We also measured the size of the team. Inspection of the correlations among these demographic variables and the key variables in the study showed that with the exception of team size and performance, there were no correlations among the control variables and our variables of interest. Thus, we tested the model with team size as a control variable ${ }^{1}$ (Bernerth and Aguinis 2016; Spector and Brannick 2011).

\section{Results}

\subsection{Analytic procedure}

To test our hypotheses, we analyzed the data as a structural equation model (SEM) using MPlus, version 8.2 (Muthén and Muthén 2007), using maximum likelihood for parameter estimation. All participants were included in the analysis, regardless of missing values in their data. However, most participants in our study completed all scales in the survey, so the amount of missing data was very low. Given the sensitivity of SEM analyses to non-normality, we inspected the skewness and kurtosis for the main variables prior to

\footnotetext{
${ }^{1}$ Inclusion of team size in the model improved the model fit, and rendered the relationship between initiated task interdependence and role clarity other significant, while before this relationship only showed marginal significance $(B=.19, S E=.11, p=.090)$. Other relationships in the model were largely the same.
}

our analyses. All variables met the normality criteria with exception of role clarity self (skewness $=-1.74, \mathrm{SE}=0.17$; kurtosis $=5.69, \mathrm{SE}=0.35$ ). To ensure that multi-collinearity was not an issue in our data (Williams et al. 2009), we assessed variance inflation factors (VIF) for all main variables, resulting in VIF scores of VIF $=1.23$ for initiated task interdependence, $\mathrm{VIF}=1.20$ for received task interdependence, $\mathrm{VIF}=1.47$ for role clarity of self, and $\mathrm{VIF}=1.49$ for role clarity of other. A VIF value that exceeds the value of 5 to 10 indicates potential collinearity issues. None of these exceeds the recommended threshold, and therefore we concluded that collinearity was not a concern in our study.

Means, standard deviations, and inter-correlations of the composite variables are listed in Table 1.

\subsection{Parameter estimation}

We specified a latent variable model, specifying each of the predictors as a latent factor based on the scale items listed above. This resulted in a model with five latent factors and 124 degrees of freedom. Parameters were estimated freely. Next to the direct paths included in Fig. 1, we allowed for the two types of role clarity to be correlated and specified effects on the opposing mediating variable. Moreover, we tested the indirect effects in the model. As mentioned above, since team size correlated significantly with role clarity of others, we included it as a control variable in the model. Thus, we regressed team size on performance as well as on both mediators.

The results show that initiated task interdependence significantly relates to role clarity of others, which in turn is significantly positively related to team performance. This confirms our Hypothesis 1 . Second, received task interdependence significantly negatively relates to role clarity of self, which in turn is marginally positively related to team performance. The direct relationship between role clarity of 
Table 2 Estimates and standard errors for main relationships, latent variable model

\begin{tabular}{|c|c|c|c|c|c|c|}
\hline & \multicolumn{2}{|c|}{ Role clarity self } & \multicolumn{2}{|c|}{ Role clarity other } & \multicolumn{2}{|c|}{ Team performance } \\
\hline & Estimate & SE & Estimate & SE & Estimate & SE \\
\hline Task interd. initiated (TI) & -0.01 & 0.10 & $0.22 *$ & 0.11 & $0.22 * *$ & 0.08 \\
\hline Task interd. received (TR) & $0.20 *$ & 0.10 & 0.09 & 0.11 & $-0.21 * *$ & 0.07 \\
\hline Role clarity self (RCS) & & & & & $0.14 \dagger$ & 0.08 \\
\hline Role clarity other (RCO) & & & & & $0.20 * *$ & 0.06 \\
\hline Team size & 0.01 & 0.01 & $0.01 *$ & 0.01 & 0.01 & 0.01 \\
\hline Indirect TI-RCO & & & & & $0.05^{\dagger}$ & 0.03 \\
\hline Indirect TR-RCS & & & & & 0.03 & 0.02 \\
\hline
\end{tabular}

$N=191$. Fit indices; $\mathrm{RMSEA}=0.06, \mathrm{CFI}=0.94, \mathrm{TLI}=0.92$

${ }^{* *} p<0.01,{ }^{*} p<0.05,{ }^{\dagger} p<0.10$ self and team performance is significant, as can be observed from the correlations in Table 1. We thus consider Hypothesis partially confirmed Hypothesis 2. Importantly, as can be observed in Table 2, the opposite relationships were not significant-initiated task interdependence was not related to role clarity of self. Moreover, the direct relationship between received task interdependence and team performance was negative. The indirect effect of received task interdependence through role clarity other on performance was marginally significant, while the indirect effect of initiated task interdependence through role clarity of self was not significant.

\subsection{Model fit}

The fit indices show that the fit for our model is acceptable, $\mathrm{CFI}=0.94, \mathrm{RMSEA}=0.06(p=0.065), \mathrm{SRMR}=0.12$. This fit is comparable to the fit of the model that does not include the relationships between initiated task interdependence and role clarity of others, and received task interdependence and role clarity of self, $\mathrm{CFI}=0.94, \mathrm{RMSEA}=0.06(p=0.078)$, $\mathrm{SRMR}=0.12$.

\section{Discussion}

We tested the prediction that two types of task interdependence, initiated and received, relate positively to team performance in distributed agile teams in different ways. Our results confirm the hypotheses that initiated task interdependence positively relates to role clarity of others and thereby influences team performance (Hypothesis 1). In contrast, received task interdependence positively relates to role clarity of the self. We also found a marginal significant effect of role clarity of self on team performance (Hypothesis 2). Initiated and received task interdependence did influence role clarity of others and self, respectively. However, initiated task interdependence was not found to be related to role clarity of self, while received task interdependence was also not significantly related to role clarity of others. Although the indirect effects in our model were not significant, the data confirm our two-step sequential logic of each type of task interdependence relating to the corresponding type of role clarity, and thereby influencing performance.

Our findings contribute to the literature on performance in distributed agile teams (Magpili and Pazos 2018). Earlier research discusses the relationship between team interdependence and team performance as unilaterally positive (Magpili and Pazos 2018), or presents it as contingent on factors, such as autonomy (e.g., Langfred 2007) or communication channels (Rico and Cohen 2005). These assumptions have, in some cases, glossed over the idea that individual team members often initiate and receive work within one team, thus promoting an over-simplified construct. In contrast to this earlier work, we describe a more elaborate relationship between team interdependence and team performance by building on the distinction between initiated and received task interdependence (Kiggundu 1983). In line with earlier discussions on the contrasting effects between these types of interdependence, we find that, whereas the direct effect of received task interdependence on team performance is negative, the effect of received task interdependence on role clarity of self is positive, which in turn influenced team performance positively. This insight shows that while received task interdependence may lead to a reduced focus on the team and an increased focus on the self, this may yield positive effects for team performance as long as the self-focus is translated into enhanced clarity of one's own role in the process. Thus, each type of task interdependence contributes in a unique way to team performance in distributed agile teams.

Moreover, each type of task interdependence has shown in this research to contribute positively towards distributed agile team performance. Building on previous research which has established the different outcomes associated with initiated and received task interdependence (e.g. Doerr et al. 2004; Kiggundu 1983; Morgeson and Humphrey 2006), we further demonstrate that the different types of task 
interdependence are not necessarily opposite influences on team performance. Instead we show how each type of task interdependence has a different effect on team performance, each based on a different underlying mechanism. By integrating the outcome of role clarity, of self and of others, we open the door for future researchers to explore the intricacies of these concepts and their outcomes.

Second, we contribute to research on how digital technologies challenge current organizational theories and research (Colbert et al. 2016; Gilson et al. 2015). Our findings from distributed agile teams create a situation in which interpersonal interactions mainly take place through digital communication, separating the processes that are intra- and interindividual more explicitly. Investigating the dependence of the individual on the other team members separate from the dependence of the other team members on the individual is a logical consequence of this set up. Thus, the nature of digital work supported the proposed relationships in the current study, which in turn leads to new insights into team performance. Importantly, future research should explore the extent to which our findings generalize across different work settings. Particularly in the increasingly digital and asynchronous environments, the often case of ambiguous role clarity can be improved with additional insight on task interdependencies.

\subsection{Managerial implications}

Our findings show that initiated and received task interdependence each can contribute to performance of distributed agile teams by clarifying the role of different team members in different ways. Organizations can capitalize on these findings by emphasizing the importance of both types of interdependence in teams. Team members in distributed agile teams often work with high levels of autonomy due to the geographical distance and increased efforts necessary to coordinate through digital tools (e.g., Hertel et al. 2004, 2005). To keep these teams performing optimally, leaders and organizations have important roles in maintaining the connections among the different members of the agile team. The current study suggests that, while connecting team members, discussing initiated and received interdependence separately may promote clarity of the roles of the different team members in different ways. Finding the right balance between these types of interdependence can help the agile team members become clear about their own roles, as well as the roles of others in their team, ultimately leading to a better performing distributed agile team.

\subsection{Limitations and suggestions for future research}

Our data are collected from individuals at a single time point, which forms a limitation to this study (Podsakoff et al. 2003).
However, as initiated and received task interdependence constitute concrete behaviors in which the individual either approaches others or is approached by others, the reverse causal relationship between task interdependence and role clarity is theoretically unlikely. It is, however, possible that our participants were biased in the extent to which they perceived themselves to be dependent on others in their team, as well as in the extent to which they perceived others to depend on them. Moreover, our sample was not too large, limiting the power of the model. This may be reflected in the reduced significance of some factors in the SEM model. Therefore, future research should focus on replicating our findings with studies that use larger samples and external ratings of some of the factors, or that measure our proposed relationships over time.

All participants in the study were working for organizations at various locations across Europe and Asia. Nonetheless, participants in our sample mainly worked in Norway. It would be interesting to investigate how other team members who locate in other offices may experience the effects described in this study. In the same line of logic, it would also be interesting to investigate how the two types of task interdependence may be actualized in distributed teams using network analyses. Although our sample could not permit such investigations, we recommend future research to look into it. Finally, we have measured participants' self-perceived initiated and received task interdependence and role clarity of self and others. In contrast to this relativist between-participants approach, it is of course possible that task interdependence or role clarity varies based on the type of team, task, or job. Moreover, the type of role clarity that employees experience most may be contingent on their job type and role in the organization. Thus, future research should take into account team-level or organizational-level variations in task interdependence or role clarity, and compare those across different types of jobs and team compositions.

Following the reasoning outlined in the introduction, we expected that each type of task interdependence would influence its respective role clarity, which would in turn positively relate to team performance. Thus, we did not expect strong indirect relationships but rather two-step chains relating the variables in our model. Nonetheless, the indirect relationship between initiated task interdependence and role clarity for others was marginally significant. In line with the earlier literature (Doerr et al. 2004; Taggar and Haines 2006), received task interdependence related negatively to team performance. As suggested, however, the effect of received task interdependence on role clarity of self was positive, as was the relationship between role clarity of self and performance. In line with our argumentation, received task interdependence can thus have a positive influence on team performance. The contradictory effects can form an explanation for the lack of indirect effect. Future research should offer further explanations. 


\section{Conclusion}

Quickly developing workplace practices and innovations have paved the path for new work arrangements, such as distributed agile teams. These teams, though already widely adopted and encouraged by organizations, come with their own challenges. In this study, we examined the roles of initiated and received task interdependence on role clarity of others and self, respectively. Our findings support that high initiated task interdependence is associated with higher role clarity of others, while received task interdependence is associated with higher role clarity of self, and that both subsequently result in higher team performance in distributed teams. Our research helps establish more applicable theory for distributed agile team work by integrating the concepts of team member interdependence with different types of role clarity to better understand how digital teams can successfully coordinate work. The results highlight the idea that different types of interdependencies facilitate distributed agile team success via different types of role clarity. These findings are useful for both leaders and members of distributed teams and suggest that organizations look into the task interdependence design within teams to improve team performance.

Funding Open access funding provided by Norwegian Business School. This work was supported by the Research Council of Norway under the Toppforsk project "Future Ways of Working in the Digital Economy" (275347) and the Slovenian Research Agency, core project "Organizing for Digital" funding J5-2555.

Open Access This article is licensed under a Creative Commons Attribution 4.0 International License, which permits use, sharing, adaptation, distribution and reproduction in any medium or format, as long as you give appropriate credit to the original author(s) and the source, provide a link to the Creative Commons licence, and indicate if changes were made. The images or other third party material in this article are included in the article's Creative Commons licence, unless indicated otherwise in a credit line to the material. If material is not included in the article's Creative Commons licence and your intended use is not permitted by statutory regulation or exceeds the permitted use, you will need to obtain permission directly from the copyright holder. To view a copy of this licence, visit http://creativecommons.org/licenses/by/4.0/.

\section{References}

Bailey DE, Leonardi PM, Chong J (2010) Minding the gaps: understanding technology interdependence and coordination in knowledge work. Organ Sci 21(3):713-730

Bernerth JB, Aguinis H (2016) A critical review and best-practice recommendations for control variable usage. Pers Psychol 69(1):229 283. https://doi.org/10.1111/peps.12103

Boshoff C, Allen J (2000) The influence of selected antecedents on frontline staff's perceptions of service recovery performance. Int J Serv Ind Manag 11(1):63-90
Burke CS, Stagl KC, Klein C, Goodwin GF, Salas E, Halpin SM (2006) What type of leadership behaviors are functional in teams? A meta-analysis. Leadersh Q 17(3):288-307

Cheng J (1983) Interdependence and coordination in organizations: a role-system analysis. Acad Manag J 26:156-162

Cheshin A, Rafaeli A, Bos N (2011) Anger and happiness in virtual teams: emotional influences of text and behavior on others' affect in the absence of non-verbal cues. Organ Behav Hum Decis Process 116(1):2-16

Colbert A, Yee N, George G (2016) The digital workforce and the workplace of the future. Acad Manag J 59(3):731-739

D'Innocenzo L, Mathieu JE, Kukenberger MR (2016) A meta-analysis of different forms of shared leadership-team performance relations. J Manag 42(7):1964-1991

de Jong SB, Bal PM (2014a) How asymmetrical task dependence and task interdependence interact: an individual level study into the effects on affective reactions. J Manag Psychol 29(8):1115-1132

Deeter-Schmelz D (1997) Applying teams to logistics processes: information acquisition and the impact of team role clarity and norms. J Bus Logist 18(1):159-178

Doerr KH, Freed T, Mitchell TR, Schriesheim CA, Zhou X (2004) Work flow policy and within-worker and between-workers variability in performance. J Appl Psychol 89(5):911-921

Dulebohn JH, Hoch JE (2017) Virtual teams in organizations. Hum Resour Manag Rev 27:569-574

Dutrénit G (2004) Building technological capabilities in latecomer firms: a review essay. Sci Technol Soc 9(2):209-241

Ford RC, Piccolo RF, Ford LR (2017) Strategies for building effective virtual teams: trust is key. Bus Horiz 60(1):25-34

Gilson LL, Maynard MT, Young NCJ, Vartiainen M, Hakonen M (2015) Virtual teams research. J Manag 41(5):1313-1337

Henderson LS, Stackman RW, Lindekilde R (2016) The centrality of communication norm alignment, role clarity, and trust in global project teams. Int J Proj Manag 34:1717-1730

Hertel G, Konradt U, Orlikowski B (2004) Managing distance by interdependence: goal setting, task interdependence, and team-based rewards in virtual teams. Eur J Work Organ Psychol 13(1):1-28

Hertel G, Geister S, Konradt U (2005) Managing virtual teams: a review of current empirical research. Hum Resour Manag Rev 15(1):69-95

Huang R, Kahai S, Jestice R (2010) The contingent effects of leadership on team collaboration in virtual teams. Comput Hum Behav 26(5):1098-1110

Jehn KA, Northcraft GB, Neale MA (1999) Why differences make a difference: a field study of diversity, conflict, and performance in workgroups. Adm Sci Q 44(4):741-763

Johnson SD, Suriya C, Yoon SW, Berrett JV, La Fleur J (2002) Team development and group processes of virtual learning teams. Comput Educ 39(4):379-393

Kahn RL, Wolfe DM, Quinn RP, Snoek JD, Rosenthal RA (1964) Occupational stress: studies in role conflict and ambiguity. Wiley, New York

Katz D, Kahn RL (1966) The social psychology of organizations, 2nd edn. Wiley, New York

Kiggundu MN (1983) Task interdependence and job design: test of a theory. Organ Behav Hum Perform 31(2):145-172

Krumm S, Kanthak J, Hartmann K, Hertel G (2016) What does it take to be a virtual team player? The knowledge, skills, abilities, and other characteristics required in virtual teams. Hum Perform 29(2):123-142

Langfred CW (2007) The downside of self-management: a longitudinal study of the effects of conflict on trust, autonomy, and task interdependence in self-managing teams. Acad Manag J 50(4):885-900 
Langfred CW, Rockmann KW (2016) The push and pull of autonomy: the tension between individual autonomy and organizational control in knowledge work. Group Organ Manag 41(5):629-657

Lyons TF (1971) Role clarity, need for clarity, satisfaction, tension, and withdrawal. Organ Behav Hum Perform 6:99-110

Magpili NC, Pazos P (2018) Self-managing team performance: a systematic review of multilevel input factors. Small Group Res 49(1):3-33

Martins LL, Gilson LL, Maynard MT (2004) Virtual teams: what do we know and where do we go from here? J Manag 30(6):805-835

Mesmer-Magnus JR, DeChurch LA, Jimenez-Rodriguez M, Wildman J, Shuffler M (2011) A meta-analytic investigation of virtuality and information sharing in teams. Organ Behav Hum Decis Process 115(2):214-225

Morgeson FP, Humphrey SE (2006) The work design questionnaire (WDQ): developing and validating a comprehensive measure for assessing job design and the nature of work. J Appl Psychol 91(6):1321-1339

Muthén LK, Muthén BO (2007) Mplus: statistical analysis with latent variables; user's guide; [version 5]. Muthén \& Muthén

Ng TWH, Feldman DC (2010) The relationships of age with job attitudes: a meta-analysis. Pers Psychol 63(3):677-718

Oldham GR, Hackman JR (2010) Not what it was and not what it will be: the future of job design research. J Organ Behav 31:463-479

Orlikowski WJ (1992) The duality of technology: rethinking the concept of technology in organizations. Organ Sci 3(3):398-427

Ortiz de Guinea A, Webster J, Staples DS (2012) A meta-analysis of the consequences of virtualness on team functioning. Inf Manag 49(6):301-308

Orton JD, Weick KE (1990) Loosely coupled systems: a reconceptualization. Acad Manag Rev 15(2):203-223

Pasmore W, Francis C, Haldeman J, Shani A (1982) Sociotechnical systems: a North American reflection on empirical studies of the seventies. Hum Relat 35(12):1179-1204

Pearce JL, Gregersen HB (1991) Task interdependence and extrarole behavior: a test of the mediating effects of felt responsibility. J Appl Psychol 76(6):838

Podsakoff PM, MacKenzie SB, Lee J-YY, Podsakoff NP (2003) Common method biases in behavioral research: a critical review of the literature and recommended remedies. J Appl Psychol 88(5):879903. https://doi.org/10.1037/0021-9010.88.5.879
Rico R, Cohen SG (2005) Effects of task interdependence and type of communication on performance in virtual teams. J Manag Psychol 20(3/4):261-274

Rico R, Bachrach DG, Sánchez-Manzanares M, Collins BJ (2011) The interactive effects of person-focused citizenship behaviour, task interdependence, and virtuality on team performance. Eur J Work Organ Psychol 20(5):700-726

Rizzo JR, House RJ, Lirtzman SI (1970) Role conflict and ambiguity in complex organizations. Adm Sci Q 15:150-163

Sarker S, Ahuja M, Sarker S, Kirkeby S (2011) The role of communication and trust in global virtual teams: a social network perspective. J Manag Inf Syst 28(1):273-310

Spector PE, Brannick MT (2011) Methodological urban legends: the misuse of statistical control variables. Organ Res Methods 14(2):287-305. https://doi.org/10.1177/1094428110369842

Sproull L, Kiesler S (1986) Reducing social context cues: electronic mail in organizational communications. Manag Sci 32:1492-1512

Stray V, Moe NB, Hoda R (2018) Autonomous agile teams: challenges and future directions for research. In: Proceedings of the 19th international conference on agile software development: companion, pp 1-5

Taggar S, Haines VY (2006) I need you, you need me: a model of initiated task interdependence. J Manag Psychol 21(3):211-230

Turban DB, Jones AP (1995) Supervisor-subordinate similarity: types, effects, and mechanisms. J Appl Psychol 73:228-234

Van der Vegt G, Van de Vliert E (2002) Intragroup interdependence and effectiveness. J Manag Psychol 17(1):50-67

Williams LJ, Vandenberg RJ, Edwards JR (2009) 12 structural equation modeling in management research: a guide for improved analysis. Acad Manag Ann 3(1):543-604

Wong SI, Berntzen MN (2019) Transformational leadership and leader-member exchange in distributed teams: the roles of electronic dependence and team task interdependence. Comput Hum Behav 92:381-392

Publisher's Note Springer Nature remains neutral with regard to jurisdictional claims in published maps and institutional affiliations. 